\title{
Energy technological complex based on the use of coal
}

\author{
M. Savina ${ }^{1, *}, G$. Mingaleeva ${ }^{1}$, and $R$. Cimbala ${ }^{2}$ \\ ${ }^{1}$ Kazan State Power Engineering University, Kazan, Russia \\ ${ }^{2}$ Technical University of Kosice, Kosice, Slovakia
}

\begin{abstract}
The paper proposes a flow chart of an energy technology complex based on thermochemical processing of solid fuels with a consistent removal of separation products. The scheme is designed for the use of coal and other solid fuels, as a result of the developed methodology for modeling the processes occurring during the thermal decomposition of the organic mass. Calculations of the circuit elements show that the thermal efficiency is increased when implementing successive separation of exhaust coal products.
\end{abstract}

\section{Analysis of the current state of complex use of coal}

Currently, technologies that allow the complex processing of raw materials are becoming particularly relevant. This allows minimizing emissions to the environment and increasing the efficiency of the production process. The most prominent example of complex processing of a mineral resource is oil refining. The highly efficient processes developed in this field make it possible to use almost all the components of crude oil. Coal and lignite are the same valuable mineral resources, because their processing allows one to get a whole range of products currently produced from petroleum [1]. In the field of processing of coal and other types of solid fuels, significant results have now been achieved and there are numerous publications concerning the integrated use of coal and the production of energy and commercial products from it. However, for the development of efficient processes and technological schemes based on them, it is necessary to study the mechanism of decomposition of the organic mass of coal and to identify the factors affecting the formation of certain components. Therefore, in this paper the authors present a diagram of an energy technology complex based on the mechanism proposed earlier in which various processes of energy production and chemical products from coal are combined.

The closest concept study is the work in which the scheme shows coal pyrolysis with possible use of intermediates [2]. Research is also being conducted to identify the influence of components on the mineral part of the organic thermal decomposition. For example, the impact of ion exchange with $\mathrm{Na}, \mathrm{Mg}, \mathrm{Ca}$ and $\mathrm{Al}$, contained in the mineral part, on evolution of $\mathrm{CO}, \mathrm{CO} 2$, moisture and pyrolysis of hydrocarbon gas, as well as on the relative yields of different gases is reflected in [3]. The combination of pyrolysis and gasification processes is also relevant. The technology proposed in [4] implies the initial pyrolysis with production of coal, tar and hydrogen-rich gas. The gas is then subjected to gasification in the stream with addition of silicon dioxide or bituminous coal with high ash content. The resulting synthesis gas passes through a purification unit and a water gas shift reactor before mixing with gas obtained as a result of pyrolysis to achieve the target molar ratio of $\mathrm{H} 2$ to $\mathrm{CO}$ equal to 2.0 , which is necessary for the synthesis of a number of chemicals.

Traditionally, coal is used in two, practically unrelated to each other, directions. Firstly, coal is fuel that, when directly burned, is used to produce heat and electricity. In this case, there are serious environmental problems associated with emissions of sulfur oxides, carbon, nitrogen, and solid particles of ash into the environment. Secondly, coal is a chemical raw material for production of coke, coal tar, alcohols, ammonia and other products. As a rule, these processes are focused on the production of any one main product, while the rest are secondary and are often not used, adding to the amount of environmental pollutants. Complex methods in this area are also in the research and development stage.

Consider the first direction. Modern requirements for operation of coal stations determine the need to clean up emissions from polluting components. During the processes of purification, i.e. ash trapping, desulphurisation and carbon dioxide emission, the secondary pollution inevitably occurs, that is, trapped components appear that must be disposed. In particular, for the production of sodium sulphate and gypsum during purification of thermal power plants emissions from sulfur dioxide, a technological scheme has been proposed, integrated into the desulphurisation unit, and economic indicators have been calculated that prove the feasibility of the process [5]. Active research is also being conducted to reduce energy consumption during desulfurization and the use of mercury removal technologies in coal-fired power units [6].

Valuable components can also be recovered from ash and slag waste, for example, aluminosilicate

* Corresponding author: pmv_83@mail.ru 
microspheres and carbon components. Modern technologies presented in [7], allow one to obtain the four major products: hollow microspheres, carbon product $(64.5 \%$ of carbon), magnetic product $(62 \%$ of iron), and alumina silicate product (no more than $3 \%$ of carbon).

Considering the second direction, the Russian technology "Carbonica" can be cited as an example of the integrated use of coal [8]. In this technology, brown coal is the optimal raw material for the combined production of thermal energy and medium-temperature coke (thermal coke), i.e. technological specialized fuel and coke substitute in metallurgy [9]. The authors used the results of experiments on the process of layer carbonization of grade $3 \mathrm{~B}$ coal of the Balakhta $\mathrm{KAB}$ deposit and developed the concept of an energytechnology complex (ETC) for processing coal into medium-temperature coke with the simultaneous production of combustible gas, which will be used to produce heat and electric energy [10]. The hardware design of such a complex is patented [11] and includes a gasifier, a boiler, a freon unit, a gas piston unit, a hydrogen separator and a programmer. The authors [12] developed a mathematical model of pyrolysis installations for low-quality solid fuels. It includes blocks for calculating the thermophysical properties of starting materials and pyrolysis products, a block for experimental data processing, as well as blocks for calculating energy and economic indicators.

\section{Development of the technological scheme of the energy technology complex based on coal usage}

As it can be seen from the previous review, the search for the optimal combination of energetic, technological, economic and environmental effect is more than relevant for creating systems in which the process takes place in one step, and all the products formed during this process are used within this system. It should be noted that the study of quantitative and qualitative composition of products at the fuel processing stage (gasification, pyrolysis) is important. Studies of the physico-chemical processes of decomposition of organic mass of coal (OMC) were carried out in $[13,14]$. Based on the kinetic model proposed in [15], a technological scheme was developed for the integrated thermochemical processing of solid fuels with the consistent removal of separation products (Figure 1).

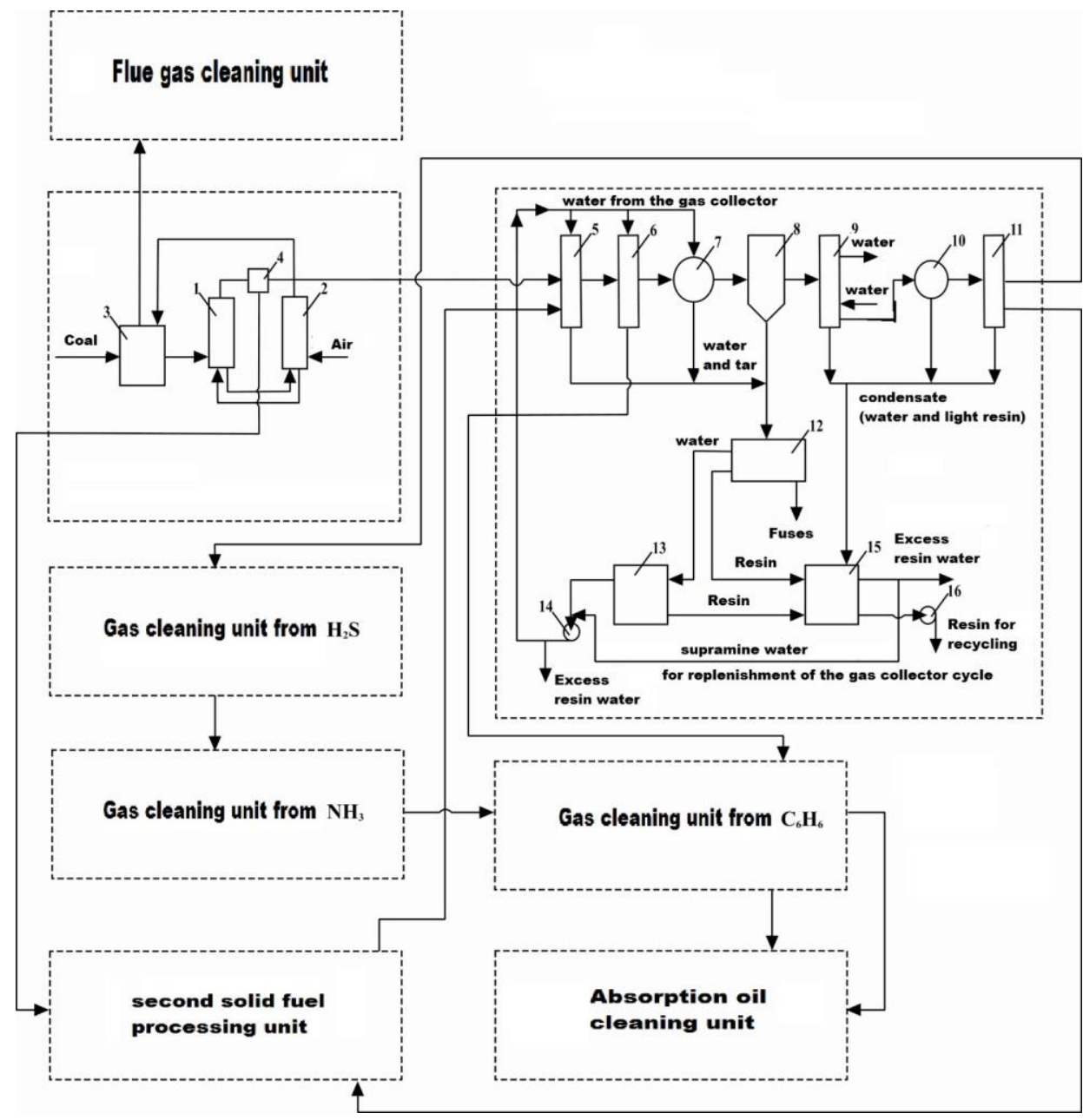

Fig. 1. Scheme of pyrolysis and removal of coal decomposition products: 1 - pyrolysis reactor; 2 - technological furnace; 3 dryer; 4 - separator of CBC and semi-coke; 5, 6 - capacitors; 7 - gas collector; 8 - separator; 9 - refrigerator; 10 - supercharger; 11 - electrostatic precipitator; $12,13,15$ - septic tanks; 14,16 - pumps. 
To remove the physically bound moisture, the coal is dried at a temperature of about $120-260^{\circ} \mathrm{C}$. Then, slow pyrolysis of all dry coal is carried out, heating to a temperature of about $427-590^{\circ} \mathrm{C}$ [16]. Next, the pyrolysis gas is subjected to multi-stage cooling with separation of the resin and the over-resin water. Part of the resin product is sent to the benzene scrubbing unit, where it is used as an absorption oil. The cooled pyrolysis gas successively passes through the purification units for hydrogen sulfide, ammonia and benzene, after which part of the gas is directed to the second fuel processing unit for synthesis of liquid products, and the other part goes to the flue gas cleaning unit. Semi-coke is sent to the second fuel processing unit to produce activated carbon used for additional purification of pyrolysis gas.

Thus, the proposed technological scheme allows implementation of an integrated energy technology processing of solid fuels to produce synthetic liquid fuels, carbon sorbents, as well as elemental sulfur or sulfuric acid.

To achieve more efficient use of the organic mass components of solid fuel, the scheme includes the following stages:

- Grinding of fuel to a pulverized state, combined with its drying;

- Pyrolysis in a fluidized bed by a solid heat carrier formed during the partial burning of coal dust in the process furnace to produce a gas-steam mixture and semi-coke;

- A step-by-step separation of steam-gas mixture, which in the first stage includes release of products that do not undergo further decomposition. In the second stage the products that allow obtaining coal oil are released, in the third stage light fraction of the resin is sent as a marketable product to the production of phenolaldehyde resins, polyamides polyarylates, etc.;

- Purification of the produced gas from hydrogen sulphide, ammonia and crude benzene (the main component of benzene), used as a raw material for chemical production, as a solvent in paint and varnish production, and as a component of motor fuel to increase the octane number, etc.;

- Obtaining of activated carbon from part of semicoke, which is used as a sorbent;

- Steam-oxygen gasification of a part of semi-coke;

- Combustion of the resulting mixture of coke oven and generator gas in the combustion chamber of a gas turbine unit with utilization of combustion products heat in the heat recovery boiler and production of steam used in the gasification of semi-coke.

Such technological scheme allows one to process stone, brown coal and peat.

In the scheme presented above, the main thermochemical processes are: cooling of the steam-gas mixture to the condensation temperature of the resin products, removal of condensable products with their subsequent separation in sumps. The processes are carried out in order to release combustible gases for combustion in the combustion chamber of GTU and waste heat boiler, the use of condensable products inside the scheme (coal tar for gas purification from benzene) and hot water. Heat balances of condensers 1 and 2 of the separation stage, gas collector, separator and sumps can be represented as the following equations (the components of heat balances are given in $\mathrm{kJ}$ per $1 \mathrm{~kg}$ of raw coal supplied to the system).

Heat balances of condensers of the 1st and the 2nd separation stages, gas collector, separator are:

$$
\begin{aligned}
& Q_{\mathrm{SGM}_{i}}+Q_{\mathrm{SW}_{i}}+A_{i}= \\
& =Q_{\mathrm{SGM}(i+1)}+Q_{\mathrm{CP} j}+B_{i}+Q_{\text {losses }}
\end{aligned}
$$

where $i, j=1,4, A_{i}=B i=0, \quad i \neq 1, A_{i}=Q_{\mathrm{AC}}, Q_{\mathrm{AC}}$ is the activated carbon heat; $Q_{\mathrm{SGM} i}$ is the heat of the $i$-th steamgas mixture (SGM); $Q_{\mathrm{SW} i}$ is heat of the $i$-th supramine water (SW); $Q_{\mathrm{CP} j}$ is the heat of condensed products (CP) of the $j$-th stage of separation.

Thus, the amount of heat that must be transferred by water is:

$$
Q_{S G M_{i}}=Q_{1 S G M_{i}}+Q_{2 S G M_{i}}
$$

$$
\text { where } Q_{1 \mathrm{SGM}_{\mathrm{i}}}=G_{\mathrm{SGM}_{i}} \times\left(\Delta H_{\mathrm{SGM}_{i}}-\Delta^{\prime} H_{\mathrm{SGM}_{i}}\right)
$$

is the amount of heat required to cool down the SGM;

$$
Q_{2 \mathrm{SGM}_{i}}=G_{\mathrm{SGM}_{i}} \times\left(\Delta H_{\mathrm{SGM}_{i}}-\Delta H_{\mathrm{CP}_{j}}\right) \text { is the }
$$

amount of heat required for condensation of SGM; $G_{\mathrm{SGM} i}$ is the steam gas mixture consumption, $\mathrm{kg} / \mathrm{h}$; $\left(\Delta \mathrm{H}_{\mathrm{SGM}_{i}}-\Delta^{\prime} \mathrm{H}_{\mathrm{SGM}_{i}}\right)$ is the difference between the enthalpies of the gas-steam mixture during cooling, $\mathrm{kJ} / \mathrm{kg} ;\left(\Delta^{\prime} H_{\mathrm{SGM}_{i}}-\Delta H_{\mathrm{CP}_{j}}\right)$ is the difference between

the enthalpies of the steam-gas mixture and condensed products during condensation, $\mathrm{kJ} / \mathrm{kg}$.

Then the required water flow rate can be found from the heat balance equation of the condensation section:

$$
Q_{2 \mathrm{SGM} i}=G_{\mathrm{W} i} \times c_{\mathrm{W}}\left(t_{2}-70\right),
$$

where $G_{\mathrm{w} i}$ is consumption of cooling agent (water) for condensation of the $i$-th stage, $\mathrm{kg} / \mathrm{s} ; c_{\mathrm{w}}$ is specific heat capacity of water at $0-100{ }^{\circ} \mathrm{C}$, equal to $4.19 \cdot 103 \mathrm{~J} / \mathrm{kg} \cdot \mathrm{K}$; $t_{2}=t_{\text {mix } i}$ is the outlet temperature, $i=\overline{1.4}{ }^{\circ} \mathrm{C}$.

The temperature of water leaving the apparatus $t_{2}$ is determined from the following heat balance equation:

$$
\begin{aligned}
& G_{\mathrm{SGM} i} \times \Delta H_{\mathrm{CP} j}+G_{\mathrm{w} i}^{\prime} \times c_{\mathrm{w}} \times t_{\mathrm{c} . \mathrm{a} .}= \\
& =\left(G_{\mathrm{SGM} i}+G_{\mathrm{w} i}^{\prime}\right) \times c_{\text {mix } i} \times t_{\text {mix } i}
\end{aligned}
$$

where $t_{\mathrm{cm} i}$ is temperature of the $i$-th mixture of condensate with a cooling agent, ${ }^{\circ} \mathrm{C} ; G_{\mathrm{W} i}^{\prime}$ is water consumption in the first approximation, $\mathrm{kg} / \mathrm{s} ; t_{\text {c.a. }}$ is the initial temperature of the cooling agent (water), ${ }^{\circ} \mathrm{C} ; c_{\text {mix } i}$ is heat capacity of the $i$-th condensate mixture with a cooling agent, $\mathrm{J} / \mathrm{kg} \cdot \mathrm{deg}$.

Thermal balances of mixing points of condensable products of the first and third stages of separation with 
separation products in a separator and heat balances of septic tanks are determined in the same way.

Thermal efficiency $\left(\eta_{t}\right)$, which in this case shows how much of the calorific value of coal is converted into useful heat, is calculated by the formula:

$$
\begin{aligned}
& \eta_{m}=\left(Q_{\mathrm{SGM} 1}^{\prime \prime}+Q_{\mathrm{CP} 2 \mathrm{st}}^{\prime \prime}+Q_{\mathrm{resin} 2}^{\prime \prime}+Q_{\mathrm{resin} 3}^{\prime \prime}+\right. \\
& \left.+Q_{\text {fuces }}^{\prime \prime}+Q_{\text {hotwater }}^{\prime \prime}\right) / Q_{\mathrm{coal}}^{\prime}+Q_{\mathrm{nt}}^{\prime a}
\end{aligned}
$$

For a typical scheme, the efficiency of the gas collector is $17 \%$. Thus, in the proposed scheme, the thermal efficiency of this unit is increased by $35 \%$.

The thermal efficiency for the entire scheme is $11 \%$. For the same scheme without separation and removal of products within the scheme, the efficiency is about $3 \%$.

\section{Conclusions}

In the developed scheme, efficiency is achieved due to the following features:

1. Thermal efficiency. In gas collectors, water is heated at $2-3^{\circ} \mathrm{C}$. Since the gas cooling is achieved mainly due to the evaporation of water, the supply of cooler water will entail a worse cooling of gas due to less evaporation. The tar water leaving the gas collector has a temperature of $73-78^{\circ} \mathrm{C}$. In the developed scheme, along with the gas collector, cooling condensers are used, the thermal efficiencies of which are 36 and $88 \%$, respectively, as a result of which the heat load on the gas collector decreases and the efficiency increases. In addition, in the condensers located in front of the gas collector, most of the vaporous resin is released, which in the traditional scheme occurs only at the cooling stage in the primary refrigerators.

2. Efficiency of using products of processing. Condensate discharged from the gas collector can be used to produce coal oil, but it requires pre-treatment. Naphthalene, which is the basis of coal oil, is isolated in primary refrigerators, which causes pollution of previously standing equipment and increases its wear. In the proposed scheme, naphthalene and hydroxynaphthalene are allocated at the 2nd stage of removal of intermediate products and can be used not only to obtain coal tar without additional purification, but also help to reduce the level of naphthalene contamination of equipment for the coke oven gas purification unit. At the stage of condensers, other condensation products can also be removed, and are usually discharged by means of a supercharger.

3. Economic efficiency. In the traditional scheme, the main resource requiring high costs is water supplied to cool down the steam-gas mixture and condensation of chemical products, since coal consumption is constant and the processing method and operating parameters influence the resulting products. With the introduction of two cooling condensers into the circuit, water consumption is reduced by 1.5 times, thereby saving resources.

\section{References}

[1] Wang J 2009 Chinese journal of catalysis 30 (8) $770-775$

[2] Radenovic A 2006 J. of Chemists and Chemical Engineers 55 (7-8) 311-319

[3] Fei Yi, Giroux Luis, Marshall Marc, oth. 2006 Fuel 85 (7-8) 998-1003

[4] Dai B, Zhang L, Cui J, Hoadley A, Zhang L 2017 Fuel Processing Technol. 155 21-31

[5] Manteca P, Martin M 2019, Industrial and Engineering Chemistry Research, 58 (15) 6155-6162

[6] Cui L, Li Y, Tang Y, Shi Y, Wang Q, Yuan X, Kellett J 2018 J. 1 of Cleaner Production 199 359-368

[7] Ryabov Y V, Delitsyn L M, Ezhova N N, Sudareva S V 2019 Thermal Engineering 66 (3) 149-168

Islamov $\mathrm{S} \mathrm{R}$, et al. Sposob polucheniya metallurgicheskogo srednetemperaturnogo koksa [Method of producing metallurgical mediumtemperature coke]. Patent RF, no. 2285715, 2006

[8] Islamov S R 2013 Thermal Engineering 60 (11) $783-786$

[9] Mixalev I O, Islamov S R 2010 Vestnik Sibirskogo gosudarstvennogo aerokosmicheskogo universiteta imeni akademika M F Reshetneva 6 (32) $145-147$

[10] Islamov $\mathrm{S} \quad \mathrm{R}$, et al. Kompleks energotehnologicheskij dlya pererabotki buryh uglej [The energy-

technological complex for processing brown coal]. Patent RF, no. 2421501, 2011

[11] Semenov S A, Gutchinskij L F, Slobodchikov I O 2010 Sistemy.Metody.Texnologii. 1 (5) 123-126

[12] Pyatygina M V, Mingaleeva G R 2010 Teploenergetika 9 67-70

[13] Pyatygina M V, Mingaleeva G R 2010 Thermal Engineering 57 (9) 802-806

[14] Bojko E A 2004 Zhurnal prikladnoj himii 77 (9) $1558-1567$

[15] Pyatygina M V, e.a. Sposob kompleksnoj termoximicheskoj pererabotki tverdogo topliva $\mathrm{s}$ posledovatelnym otvodom produktov razdeleniya [Method for complex thermochemical processing of solid fuels with subsequent separation of separation products]. Patent RF, no.2464294, 2012 